\section{Abstract}

Fires in underground mines may pose a challenge to fire and rescue personnel where the complex environment and multiple influences of a fire are poorly considered during pre-incident planning. A better knowledge of pre-incident planning in underground mines would improve the safety of personnel. This study on pre-incident planning in underground mines applied data from experiments, inventories and design fire studies. A number of questions were considered related to information sources, fire modelling, capturing complexity and using fire scenarios. When performing fire modelling, empirical models could be used to complement other modelling tools. The study found that for modelling of spatially extensive mine sections, the use of ventilation network-based mine fire simulations could be a better option. Using an analytical toolbox, an iterative testing of plans and an ongoing planning process, the pre-planning challenges for a mine can be mitigated. The purpose of this study was to examine existing pre-incident planning and propose information sources, tools and specific actions for future plans.

\title{
Pre-incident planning of fires in underground hard rock mines: old and new risks
}

Peer Reviewed

\section{Rickard Hansen ${ }^{1}$}

1. University of Queensland, Brisbane, Queensland.

\section{SUBMITTED}

22 June 2021

\section{ACCEPTED \\ 26 July 2021}

DOI

www.doi.org/10.47389/36.4.68

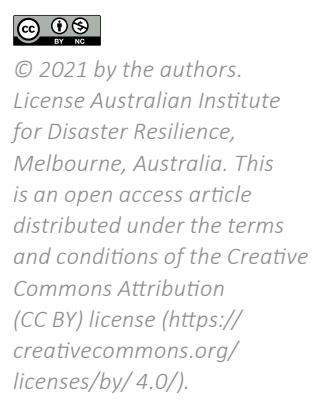

\section{Introduction}

Fires in underground mines pose challenges that include the 3-dimensional feature of the mine, long distances filled with smoke and the limited number of routes to access the fire. Existing risks include smoke spread, falling rocks and fires affecting the ventilation flow. New risks may include the introduction of battery-powered mine vehicles with different fire behaviour, emission of toxic substances and the changing conditions that fire and rescue personnel will face.

A key tool during fire and rescue operations is pre-incident planning, which assists personnel in the decision-making process and can remedy the initial lack of information. The main issues with pre-incident planning in underground mines are the complex mining environment, the ever-changing layout of the mine and the highly transient and numerous ways a fire will behave.

This paper studies pre-incident planning in underground hard rock mines and proposes information sources, modelling tools and contents of these plans. Questions considered are: What information sources to use? How to use fire modelling? How to capture the complexity of the mine? Data and findings from fire experiments, inventories and design fire studies were applied in this study.

Earlier work on pre-incident planning has focused on pre-planning in general and does not address specific risks, challenges and conditions found underground. Perry and Lindell (2003) reviewed emergency planning and its relationship with training, practising and written plans. Chen and co-authors (2007) discussed critical issues to coordination in emergency contexts where response pre-planning was one of the highlighted issues. Byler and Hartwell (2009) conducted a study on the implementation of a fire incident pre-planning system and analysed existing tools to design a fire incident pre-plan worksheet. Baker (2011) looked at the general procedures and structures of pre-incident planning and discussed sections typically found in pre-incident plans. Seaton and co-authors (2019) studied the effective use of information resources at each phase of a chemical hazard emergency. However, studies on 
pre-incident planning in underground mines are few. KowalskiTrakofler and co-authors (2010) studied the initial response during an underground mine emergency and discussed the preplanning in general terms. To fill this gap, this study is constrained to the pre-incident planning of fires in underground hard rock mines, as the risks differ compared to other types of mines.

\section{Pre-incident planning of fires}

A pre-incident plan comprises of collected and refined information on a certain object. The refined information could include fire modelling and simulations. The plan is used to aid fire and rescue personnel when determining an incident response and provides adequate and sufficient information. Further descriptions on pre-incident planning are in NFPA 1620 (NFPA 2020) and Perry and Lindell (2003).

\section{The pre-incident planning process}

The pre-incident process consists of stages as shown in Figure 1. The process starts with the gathering of data and site inventories, where risks are documented and layouts collected. An evaluation of the data takes place where it is decided what data to proceed with, what data to refine further and how to

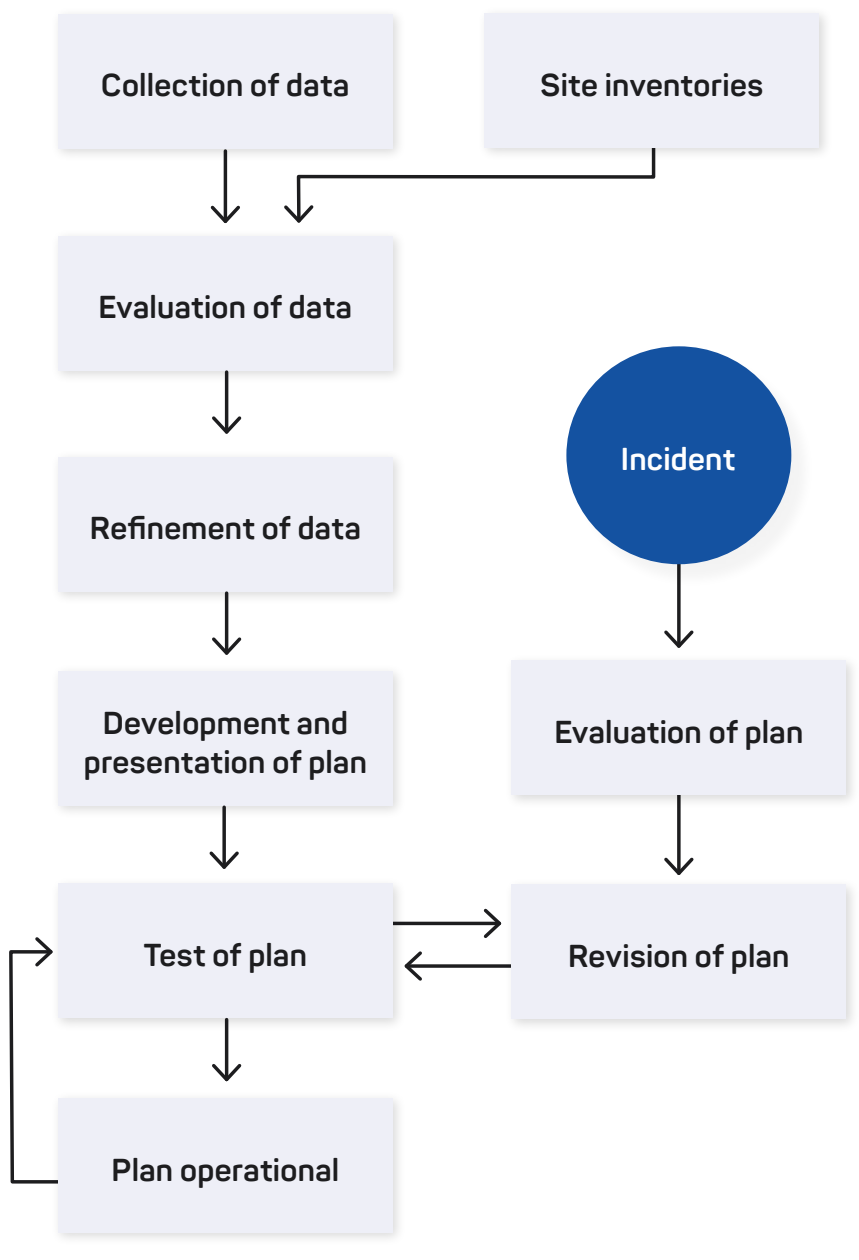

Figure 1: Example flowchart of a pre-incident planning process. present the plan. The data refinement may include the use of a modelling tool or risk analysis. The next stage is the development and presentation of a draft plan, which will be tested and practised. The outcome of the tests may result in a revision of the plan before an operational version of the plan is ready for use. Planning is a continuous process as the layout of the object may change and new risks may arise. An occurring incident presents an opportunity to correct errors and improve the plan. Figure 1 is an example of this process and other approaches can be found in NFPA 1620 (NFPA 2020).

\section{Data components}

The contents of a plan will vary depending on the type of object. NFPA 1620 (NFPA 2020) lists the components of a pre-incident plan as:

- site considerations, such as the construction of building and external site conditions

- occupancy considerations, such as the means of egress and on-site emergency organisation

- water supply and fire protection systems, such as water hydrants and automatic sprinkler system

- special considerations such as hazardous materials and abandoned structures.

\section{Fire experiments, inventories and design fire studies}

Vehicle fires are the most frequently occurring fire in underground mines (De Rosa 2004, Hansen 2018). As such, 2 fire experiments were conducted in an underground mine involving a loader and a drilling rig (see Hansen \& Ingason (2013)) for a full description of the experiments).

Hansen (2010a) conducted site inventories of underground mines to investige the location, frequency and configuration of combustible materials and fire protection systems.

A design fire study in underground mines was conducted by Hansen (2010b) that included derived design fire scenarios. Hansen (2019) also presented design fire scenarios using input parameters from the Australian mining industry.

\section{Pre-incident planning: process, data, tools and contents}

The components discussed and proposed should be regarded as a typical collection for underground mines, but not as a comprehensive list for all mines. The proposed tools, scenarios and components are not applicable to all mines. The characteristics of the mine and specific risks will dictate the extent and content of the planning process. In addition, legislation and organisations may vary from country to country and will influence the planning process and contents.

\section{The pre-incident planning process}

The nature of mines will be reflected in the planning process, where functions and areas of interest will differ. A key function 
is mine ventilation, which is critical during the evacuation phase as well as the fire suppression and recovery phases. Mine plans will be an asset during the planning process as will details of mine water supplies, electrical power, communication and personnel responsible for fire protection systems. Details of each system, the redundancy of each system and possible alternative systems or backups are essential. Given the high risk of vehicle fires underground (Hansen 2018, De Rosa 2004), personnel responsible for the vehicle fleets should provide details on vehicle types and distribution of vehicles across the mine. Rock mechanics personnel may be able to provide details on the effects on the surrounding rock for a specific fire scenario. Fire and rescue personnel provide expertise on the management and coordination of an incident and the capability of fire and rescue organisations.

Site personnel could be control room personnel or personnel from a specific mine section. Control room personnel could be involved in the planning process particularly given the likelihood of a command post being established in the vicinity of the control room. Control room personnel may also provide a good overall picture of processes and flows of the mine. Personnel from the mine section may provide details on the localised processes, risks or inputs to cascading effects.

Ensuring personnel and diversity of functions are included in the planning improves the robustness of the plan, the knowledge of the plan and the overall readiness of the organisation. Preincident planning is an ongoing process as new sections of mine are changed and added and older parts are closed.

\section{Information sources}

A fundamental information source is a fire-risk analysis that includes valuable information about earlier fires, fire causes and points of origin. Hansen (2018) studied incident data from the mining industry in New South Wales, Queensland and Western Australia, which can assist in evaluating mine sections with different vehicles or equipment. The study found that the vehicle types most frequently involved in fires were trucks, loaders, drill rigs and dozers and the most frequent start position was the engine bay.

Results from the risk analysis are a good basis for deciding what risks to highlight in the plan and what risks and mine sections to analyse further. Including data from the mining sector helps to address uncertainties with a small number of incidents occurring in a mine or the uncertainties connected with a new risk being introduced.

The risk analysis provides a basis for developing design fire scenarios for different mine sections. The output from design fire scenarios provides a good basis for analysing fire behaviour and testing plans. While the actual risk analysis, design fire scenarios or modelling analysis may not be included in the plan, the findings from the analysis and scenarios should be included. The findings would be included when listing existing risks, describing how the mine ventilation system should be managed and what access routes should be used.
Given the complexity of underground mines and the added challenge of a fire, testing the plan is particularly important to reduce uncertainties. Complexity will increase demands on the testing process and an analytical approach is preferred. An analytical approach (design fire scenarios, modelling) identifies otherwise unforeseen developments or captures the multifaceted nature of a mine fire. The use of design fire scenarios is a good tool for testing the plan as it is a tactical exercise and checkpoint during the process. The testing implies an iterative process between the refinement of data and testing of the plan (Figure 1).

The use of modelling tools, refined data, iterative testing of plans and the ongoing planning process will mitigate the challenges of a fire underground and will increase the efficiency of the response and the safety of people.

The design fire concept includes a comparison of existing or planned fire protection measures and the risk to personnel and mining operations for a given scenario. A design fire scenario should also be tested against the response of the fire and of rescue personnel as well as management of the mine ventilation and other factors. The heart of design fire scenario work is developing a heat release rate curve from which temperature distribution and smoke spread can be calculated and used as input to a fire model. Hansen (2015) provides information on the development of heat release rate curves. In applying the design fire concept, it is possible to evaluate the effects of a fire that has not yet occurred but could possibly occur. When identifying design fire scenarios for an underground mine, the unique risks and challenges should be covered. Hansen (2019) listed fire scenario characteristics in underground mines as:

- a fire with a rapid-fire-growth rate at an early stage, affecting the primary evacuation route/s

- a fire with extensive smoke production over a long time

- an extensive or fast-growing fire near an area with a large number of personnel

- a fire with continuous fire spread, resulting in a long-lasting fire with a high heat release rate

- a fire where the smoke control system fails to function, leading to extensive smoke spread

- a fire that goes undetected for a long time, resulting in a considerable fire growth and heat release rate

- a fire with longer and intermittent periods with high heat release rates and with sudden increases of heat release rates (the fire may cause problems during the smoke extraction and the rescue operation).

Most of these fire scenario characteristics do not contain information on the position of the fire. The position of the fire scenarios has to be determined for each mine based on the risks and layout. Several positions for each fire scenario should be applied to increase the robustness of the pre-incident plan. The decaying phase of the design fire scenario will be of great interest when evaluating the life safety aspect. The decaying phase may entail persistent smoke production, which will hamper evacuation of people from refuge chambers (Hansen 2019). 
" RESEARCH

Unique information sources for underground mines could be the spatiotemporal distribution of the personnel underground. Due to long distances underground and extensive smoke spread, it is important to locate personnel so that fire and rescue resources can be directed in an efficient way. A positioning system underground is a great asset but having a good decision basis in the pre-incident planning will be important for prepositioning resources and assigning evacuation routes and assembly points.

Data on traffic flows and traffic patterns provides details on the transportation of hazardous materials and of large fuel loads. In addition to exposing transportation risks, the data could be used to develop design fire scenarios. The spatiotemporal distribution of mining vehicles provides data to analyse probable fire behaviour at different mine sections or when analysing possible evacuation flows. Manuals and design plans of vehicles and other equipment provide details on fuel load, which will be essential information when developing design fire scenarios.

\section{Data refinement}

The refinement of data includes conducting risk analysis and design fire scenarios. The refinement includes extraction of data from the design fire scenarios for processing when looking into cascading effects and alternative chains of events. The processing of data could involve taking the design fire scenarios further and modelling smoke spread and evacuation activities.

\section{Fire modelling}

Fire modelling is performed using either empirical models, a ventilation network based mine fire simulation software or a Computational Fluid Dynamics (CFD) software.

Applying empirical models can rapidly produce a result and can focus on a single phenomenon such as the fire's throttle effect or backlayering. Both the throttle effect and backlayering have a profound effect on smoke extraction and the rescue operation and should be included in the planning (Hansen 2020, Thomas 1968). Possible limitations of an empirical model are that the model is not valid for underground conditions or that steady-state conditions are assumed in the model. The latter can be remedied by using a quasi-steady process where, at any instance in time, the parameter can be described as if the surface or volume were exposed to a steady-state situation. When modelling large mines, the use of the quasi-steady process may become cumbersome and the use of ventilation network based mine fire simulation software could be an option. This can solve the complex mine ventilation system, where parameters are combined and solved iteratively (Hansen 2010a). It is thus possible to obtain fast and transient solutions even though the simulated system is vast and complex, which explains its frequent and long usage in the mining industry. Limitations of the software can be described using 2 assumptions (Hansen 2010a):

- unidirectional flows are assumed in the mine drifts and declines, which is seldom the case in the near field of the fire - immediate and complete mixing of gases is often assumed, which rules out a stratified flow near the fire.
CFD models are used to predict fluid flows, heat transfer and other aspects during a fire. The setup of the input file for a mine can be time consuming, whereas ventilation network-based mine fire simulation software contains predefined parameters and can be specifically developed for mining conditions. With a CFD model, it is possible to model the area closest to the fire, accounting for multi-directional flows. Due to the high computational requirements of a CFD model, using a CFD model for an entire mine would be improbable and questionable. Instead, a CFD model should be used for the near field of the fire and provide input to ventilation network-based mine fire simulation software for the remaining parts of the mine where a unidirectional flow is more probable.

The results of the fire modelling provide valuable data when writing and testing the plan with respect to mine ventilation and evacuation safety. It is unlikely that a CFD simulation would be performed during an ongoing incident due to the high computational requirements. However, empirical models and ventilation network-based mine fire simulation software could be applied and available predefined scenarios in the software could speed up the process.

\section{Evacuation modelling}

When modelling evacuation, an egress simulation model could be used. Most models are intended for buildings and will not be suited for the underground where evacuation may take place on foot, by elevator and by vehicle. The evacuation process may include intermediate stops and using refuge chambers before evacuation to the surface takes place.

Given the generally low numbers of personnel underground, an unimpeded evacuation flow might be assumed. A simple equation-based approach could be used to calculate the movement of personnel by dividing the distance to a refuge chamber or intermediate assembly point with the assumed movement speed to obtain the movement time. This gives a rough estimate of the time needed and considerations are required with respect to physical obstructions and reduced movement speeds connected with increased numbers of personnel, as well as visitors and contractors who are less familiar with the surroundings.

Both the spatiotemporal distribution of mining personnel and vehicles serves as fundamental input data, describing the starting positions of the personnel and vehicles at the initiation of the evacuation. Typical movement speeds in different mine sections will be important information. Movement speeds applied in tunnels could be used, but the differences between 2 types of objects should be considered. A higher movement speed could generally be expected in a mine as personnel are familiar with the surroundings. The pre-evacuation time (time before an individual initiates evacuation after being notified) should be added to the movement time to obtain the time required for evacuation.

The time required to evacuate a mine section should be weighed against the time to untenable conditions in the mine section (provided from the fire modelling, see Porzycki, SchmidtPolończyk and Wąs (2018)), where visibility can serve as a 
suitable criterion due to extensive smoke spread underground. Results of the evacuation analysis and modelling provide valuable data when testing the plan and planning deployment of rescue resources, defining access routes and assembly points or mine ventilation management.

\section{Cascading effects}

A fire underground can spread beyond the start object and fire gases can affect installations further away. The ignition of adjacent fuel or the smoke spread may initiate further risks. These cascading effects need to be identified and analysed and included in the plan. When analysing cascading effects, input data from risk analysis of mine sections, descriptions of the production process and range of effects from a fire are valuable assets. Cascading effects could be identified and described in the plan, enabling fire and rescue personnel to break the chain of events and mitigate the consequences.

\section{Alternative chains of events}

One of the key parts of pre-incident planning is alternative chains of events, which increase the number of tactical options available and provide room for manoeuvre. The planning covers the different directions that an incident can take and developing backup plans and actions. The planning includes analysing possible scenarios and preparing tactical options to counter the sequence of events. Preparing tactical options includes obtaining or prepositioning specialised equipment and training of personnel for specific situations.

Underground mines with limited access routes and ventilation options increase the need for planning. The sensitivity and vulnerability in case of a system failure increases the need for a backup plan.

\section{Components with an underground perspective}

\section{Access routes}

Access routes must be carefully planned as the number of access routes may be limited and will need to serve as attack routes and as evacuation routes. Preferably, the routes should be divided into primary and alternate attack and evacuation routes to limit the risk of the 2 operations interfering with each other. When determining access routes, parameters such as the position of the fire and existing fire and smoke barriers should be considered. The selection of access routes should be synchronised with the management of the mine ventilation during a fire. The choice of access routes will not be static but will vary from fire to fire and during a fire.

When planning the evacuation by vehicle, the aim is to prevent traffic jams and ensure a steady traffic flow. There is also the possibility of vehicles driving through smoke with limited visibility. Designated access routes for specialised equipment and vehicles should be verified to ensure accessibility and the possibility of turning the vehicle around. Positions deemed critical could be identified in the plan and actions to facilitate the turnaround (such as lighting) should be considered. The inclination of the decline could be included if it affects the accessibility. The transportation time to reach positions underground could be included in the plan.

\section{Fire protection systems}

Plans should list existing automatic fire suppression systems as well as contain information on the design of the system. Information should be specific: is the suppression system designed to extinguish the fire or is it designed to contain the fire? A fire suppression system in a parking drift with large mine vehicles may be designed to contain the fire. This information is required when additional fire suppression resources are sent to the site and a prolonged smoke production could be expected.

The general lack of fire doors or barriers in a decline and the high frequency of vehicles makes a design fire scenario applicable (Hansen 2010a). The result will be helpful when planning for evacuation, alternative chains of events and the management of the mine ventilation.

\section{Ventilation system}

Pre-planning involving the ventilation system should include instructions on how to manage the ventilation system in case of a fire in a mine section. The instructions would specify what fans should be running or not and doors that should be open. The plan should also contain positions of fans, shafts, refuge chambers and places where fresh air can be found. The plan should be verified against design fire scenarios for the mine section. Backup actions should be planned in case of a loss of power or closed fire barriers. Sites critical with respect to the mine ventilation should be identified and monitored, and backup plan actions initiated if a barrier malfunctions or the smoke spreads in an undesired direction.

The fire growth rate and heat release rate of vehicle fires can be very high due to the fuel load on vehicles. A high heat release rate will cause backlayering and severe smoke production and a high fire growth rate may initiate a throttle effect that seriously affects mine ventilation (Hansen 2020). Figure 2 shows the heat release rate of a loader in an underground mine (Hansen \& Ingason 2013). The initial fire growth and heat release rates are very high and cause problems to the mine ventilation. A second peak in the heat release rate can be seen after approximately 50 minutes. This is due to the fuel igniting or being engulfed at later stages. Therefore, periods of peak heat release rates can be expected at later stages. The duration of the fire is considerable and must be considered when planning for the evacuation from refuge chambers. Figure 3 displays the heat release rate from a drilling rig experiment (Hansen \& Ingason 2013). The drilling rig fire involved practically all the combustible fuel items in the early phases, which is seen in the single peak and the high heat release rate.

When developing design fire scenarios, changes in the velocity or direction of ventilation during the incident (starting or ramping up fans or if a ventilation duct burns up) should be considered. A change in the direction or magnitude of the ventilation flow will result in a different smoke spread and also in a different heat release rate (Hansen 2019). 
M RESEARCH

Additional scenarios to be considered in planning:

- A fire is positioned at the intake of the main airway above ground and smoke spreads downwards into the mine. The fire could result in an extensive and rapid smoke spread that affects large areas and decrease time available for evacuation.

- A vehicle fire takes place close to either an intake fan or an intake shaft. The ventilation will initially aid the smoke spread and cause problems during evacuation.

\section{Evacuation}

Due to the long distances underground and the limited number of evacuation routes, evacuation plans will differ from those used for above ground. The differences lie in the use of refuge chambers, the use of vehicles to reach a safe place and intermediate assembly points (where personnel are counted and wait for instructions whether to remain in place, head to another safer place or leave the mine). Communicating to the personnel underground what evacuation routes is of upmost importance. The progress of the evacuation also needs to be communicated to rescue crews to ensure issues are quickly solved and rescue resources are used efficiently. Backup plans in case of communication failure should be established.

The use of positioning systems underground should be planned and coordinated. Also, planning for evacuation of injured people from a refuge chamber, of personnel through smoke or of a large number of personnel from a site should also be considered.

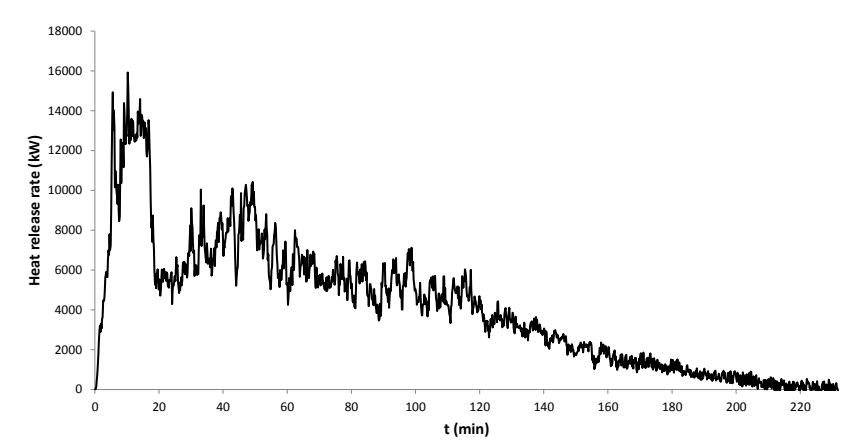

Figure 2: The heat release rate from the loader experiment (Hansen \& Ingason 2013).

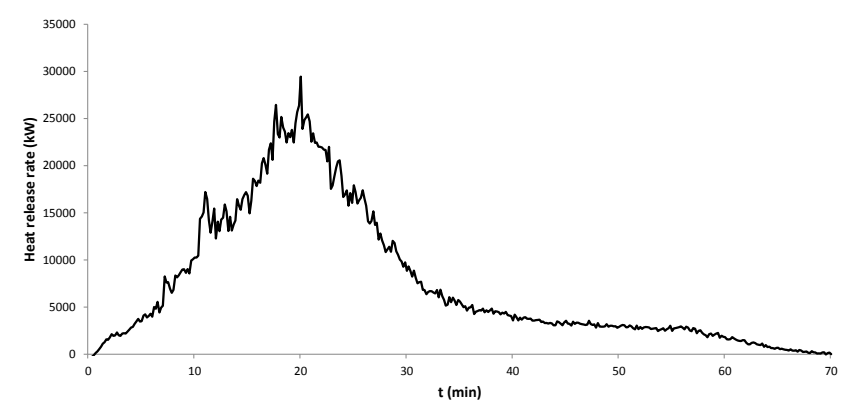

Figure 3: The heat release rate from the drilling rig experiment (Hansen \& Ingason 2013).

\section{Special considerations}

Mines change as do their risks. According to Hansen (2010b), transient risks include:

- maintenance stops with hot works conducted and large amount of combustible material transported, and where the number of personnel underground increases considerably

- intermittent transports with explosives and flammable liquid in declines

- a temporary increase in the number of fire and rescue personnel, backup plan actions or countering cascading effects.

In some mine sections, smoke production may be extensive and is highly undesirable as it leads to smoke spread. This has a negative impact on the evacuation and mine ventilation as well as the fire and rescue operation. Examples where extensive smoke production occurs include conveyor drifts and workshops containing large amounts of tyres or flammable and combustible liquids (Hansen 2010a).

Abandoned parts of a mine may contain combustible material and fire protection systems may have been removed. A fire occurring in an abandoned section may go on for a long time before being detected and the fire size may be considerable. This can affect evacuation, mine ventilation and fire suppression activities.

\section{Fire and rescue operations}

In most circumstances, external firefighting resources might be used. Pre-planning could include the experience and qualifications of personnel and the need for additional training, specialised equipment and guides related to mine conditions as well as prior rehearsals for specific parts of operations.

An incident may require one or several staging points above ground and underground as well as several attack routes. The designated staging points serve as fresh air bases and turning places. When planning staging points, an evaluation is required of mine ventilation, communication, accessibility to route networks, turn-around places and other nearby risks.

Hansen (2019) indicated that design fire scenarios may cause risks and be challenging for fire and rescue operations. Figure 4 illustrates the heat release rate of a vehicle fire in a decline with longer and intermittent periods with high heat release rates occurring long after the start of the fire. The long periods of high heat release rates and the sudden increase of heat release rates adds to risks for the fire and rescue personnel.

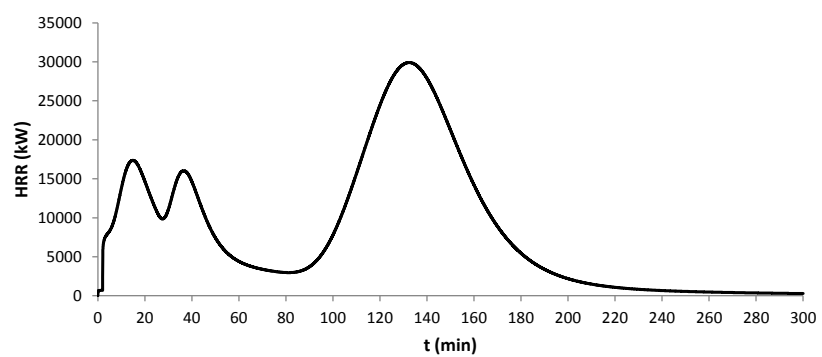

Figure 4: The heat release rate of a fire with intermittent periods with higher heat release rates (Hansen 2019). 


\section{Conclusions}

To investigate pre-incident planning of fires in underground mines, data was applied from fire experiments, inventories and design fire studies. It is recommended that empirical models focusing on specific phenomena be used to complement other modelling tools. The use of empirical models may be cumbersome and using ventilation network-based mine fire simulation software is an alternative. Design fire scenarios and modelling results are a key tool when analysing fire behaviour and testing the plan and act as a checkpoint during the planning process. Mine ventilation systems should have instructions on how to manage the system and how to test it against design fire scenarios for mine sections and backup actions. By using analytical tools, iterative testing of plans and ongoing planning process, the high risks of fire in an underground mine can be mitigated.

\section{References}

Baker FJ 2011, Fire Pre-Incident Planning - Understanding if There is a Problem. In: ASSE Professional Development Conference and Exposition. American Society of Safety Engineers.

Byler DJ \& Hartwell RD 2009, Structure Fire Preplans. Project Number: ASR-BH09. Worcester Polytechnic Institute, Worcester, Massachusetts.

Chen R, Sharman R, Rao HR \& Upadhyaya SJ 2007, Emergency Response Coordination and IT support: Contingency and Strategies. The Americas Conferences on Information Systems, Keystone, Colorado, August 9-12, 2007.

De Rosa MI 2004, Analysis of mine fires for all US metal/nonmetal mining categories, 1990-2001. NIOSH.

Hansen R 2010a, Site inventory of operational mines - fire and smoke spread in underground mines. Work report SiST 2010:1. Västerås: Mälardalen University, Sweden.

Hansen R 2010b, Design fires in underground mines. Research report SiST 2010:2. Västerås: Mälardalen University, Sweden.

Hansen R 2015, Analysis of methodologies for calculating the heat release rates of mining vehicle fires in underground mines. Fire Safety Journal, vol. 71, pp.194-216.

Hansen R 2018, Fire statistics from the mining industry in New South Wales, Queensland and Western Australia. Brisbane: The University of Queensland.

Hansen R 2019, Design of fire scenarios for Australian underground hard rock mines - Applying data from full-scale fire experiments. Journal of Sustainable Mining, vol. 18, pp.163-173.

Hansen R 2020, Mass flow during fire experiments in a modelscale mine drift with longitudinal ventilation. Mining Technology, vol. 129, pp.1-14.

Hansen R \& Ingason H 2013, Heat release rate measurements of burning mining vehicles in an underground mine. Fire Safety Journal, vol. 61, pp.12-25.
Kowalski-Trakofler KM, Vaught C, Brnich Jr. MJ \& Jansky JH 2010, A Study of First Moments in Underground Mine Emergency Response. Journal of Homeland Security Emergency Management, vol. 7, no. 1, 2010. doi:10.2202/1547-7355.1652

NFPA 2020, NFPA 1620 (Standard for Pre-Incident Planning). National Fire Protection Association, Quincy

Perry RW \& Lindell MK 2003, Preparedness for emergency response: guidelines for the emergency planning process. Disasters, vol. 27, no. 4, pp.336-350.

Porzycki J, Schmidt-Polończyk N \& Wąs J 2018, Pedestrian behavior during evacuation from road tunnel in smoke condition-Empirical results. PLoS One. 2018, vol. 13, no. 8. doi: 10.1371/journal.pone.0201732

Seaton MG, Maier A, Sachdeva S, Barton C, Ngai E, Lentz TJ, Rane PD, Taylor McKernan L 2019, A framework for integrating information resources for chemical emergency management and response. American Journal of Disaster Medicine, vol. 14, pp.33-49.

Thomas PH 1968, The movement of smoke in horizontal passages against an air flow. Fire Research Note, no 723, Fire Research Station, Watford, UK.

\section{About the author}

Dr Rickard Hansen is a researcher and a fire protection engineer at the Sustainable Minerals Institute at the University of Queensland, specialising in fires in underground hard rock mines. He has more than 25 years' experience as a fire officer and fire protection engineer. 